\title{
Comparative study of Carica papaya with marketed product for the treatment of wounds in diabetic rodents
}

\begin{abstract}
Diabetes is an unending situation associated with peculiarly elevated levels of sugar (glucose) in the blood. This chronic illness is also related with the degenerative extended pathological disorders like retinopathies, nephropathies, atherosclerosis, wound healing problems and cataract. Insulin a hormone prepared by pancreas helps glucose from foodstuff get into your cells to be utilised for energy. Due to overtime the large amount of glucose in your body can results for health problem also. Tissue renovates and wound curing are complicated processes that engross inflammation, granulation and tissue remodelling. Wound curing is characterised by two stages via inflammation and proliferation. The extract of Carica Papaya fruit has been checked for its wound curing nature in streptozotocin induced diabetic rats by using excision as well as dead space wound models. The therapeutic utilisation of Carica Papaya relies because of the existence of papain an active constituent. Carica Papaya have antimicrobial, antioxidant and anti inflammatory behaviour which provoke us to ensure the wound curing property of following drugs on wound healing specially on diabetic rodent. This whole study emphasize on the effect of diabetes (high blood glucose sugar level) on the wound curing rate of rodents. Diabetes was induced by using streptozotocin and the blood glucose estimation was performed on tail vein blood by using a glucometer accu check wistar rats whose fasting blood glucose levels exceeded $250 \mathrm{mg} / \mathrm{dl}$, were measured as diabetic.
\end{abstract}

Keywords: carica papaya, wound healing, diabetes, streptozotocin
Volume 5 Issue I - 2018

\author{
Akash Yadav,' Shaily Chaudhary² \\ 'IPS Academy College of Pharmacy, India \\ ${ }^{2}$ Smriti College of Pharmaceutical Education, India
}

Correspondence: Akash Yadav, IPS Academy, College of Pharmacy, Knowledge Village, Rajendra Nagar,A.B. Road, Indore, Madhya Pradesh, India, Tel +9I-9907586213, Email akash.ipsa@gmail.com

Received: October 15, 2017 | Published: January 12, 2018

\section{Introduction}

The quote for diabetes is diabetes can hit anyone, from any walk of life and it does in numbers that are significantly increasing. According to the previous decade, the figures of people having diabetes jumped about 50 percent to more than 29 million Indians. Globally, it affects greater than 380 million individuals and the World Health Organization concludes that by 2030 , the percentage of individuals having diabetes will be greater than two times. In the present scenario, diabetes hacks more lives in comparison to AIDS and cancer combined claiming the life of 1 Indian every 3 minutes. It is a main cause of heart failure, blindness, amputations, amplified wound healing rate increased thirst, kidney failure, urination, increased hunger, fatigue, blurred vision, lack of sensation or prickling in the feet or hands sores that do not heal easily, inexplicable weight loss and stroke. Symptoms of type 1 diabetes can appear suddenly even in a few weeks. Symptoms of diabetes mellitus type II usually appear gradually over the course of a number of years and can be so calm that one might not even see them. Number of individuals suffering from diabetes type 2 has no sign and symptoms. Even the few number of people do not find out that they have they are suffering from the disease until they have diabetes linked health issues, such as heart trouble or blurred vision. Type 1 diabetes happens when the immune system, the body's system for fighting illness, diminished and destroys the insulin-producing beta cells of the pancreas. It is found that the one is more possibility to develop type 2 diabetes mellitus 3 if they are less physically active and are flabby or obese. Over weight many times causes insulin resistance and is general in individuals with type 2 diabetes mellitus. ${ }^{1-5}$
Wounds occur when the skin is broken down or scratched due to injury. Reasons of damage may be the effect of thermal, mechanical, chemical, electrical, or nuclear sources. The skin can be injured in a many ways depending upon the technique of injury. Inflammation is the skin's preliminary reaction to injury. Superficial (on the surface) wounds and abrasions depart the deeper skin layers intact. Such types of wounds are recurrently caused by friction rubbing against a scratchy surface. Deep abrasions (cuts or lacerations) go through all the layers of the skin and into underlying tissue like muscle or bone. Proper wound care is necessary to avoid infection, be sure there are no other associated injuries. A weaken immune system, diabetes and other malfunctioning or diseased systems reduce the capability of the human body to shield it against infections, inflammations, ulcers or wounds. ${ }^{6-10}$

Streptozotocin (STZ) is a naturally occurring chemical, formerly known as an antibiotic, and later on studies found that it is mainly toxic to the insulin-producing beta cells of the pancreas. Streptozotocin is a established diabetogenic compound, produced by the gram positive soil bacterium Streptomyces achromogenes. It is largely used experimentally as a mediator able for producing insulin-dependent diabetes mellitus (IDDM), also recognized as diabetes mellitus type 1 (T1DM). That's why streptozotocin is broadly used to cause diabetes in rodents. ${ }^{11-14}$ Carica Papaya is usually used to treat various skin disorders, including wounds. It is generally used in budding countries as an efficient and readily available treatment of wounds, mainly burns. Papaya is the most excellent fruit for incorporating in your skin care regime because it consist of an enzyme called 
papain which is responsible for whitening skin, dropping extra hair, exfoliating dead skin, repairing ageing skin etc. This papain enzyme is present in greatest concentration just below the peel of papaya. The papain enzyme helps in curing of the wound as well as also makes the bacteria apart and prevents the wounds from getting bigger. One can put the flesh of papaya fruit on fresh cuts, wounds, and even on burns to enhance a fast recovery. ${ }^{15-18}$

\section{Material and methods}

\section{Materials required}

Streptozotocin, Glucometer, Accu chip, Povidone iodine ointment, Carica Papaya gel and wistar rats.

\section{Induction of diabetes}

Diabetes (DM) was induced chemically as mentioned by $\mathrm{Wu}$ et al. ${ }^{1}$ Briefly after 12 hour fast, rats received one intra peritoneal (i.p.) injection of streptozotocin $(65 \mathrm{mg} / \mathrm{kg})$ freshly prepared in sodium citrate buffer of $0.1 \mathrm{M}(\mathrm{pH} 4.5)$. At 8th day after streptozotocin injection blood glucose measurement was performed on tail vein blood by using a glucometer Accu-Check. Rats those fasting blood glucose level is more than $250 \mathrm{mg} / \mathrm{dl}$ were measured as diabetic. Water intake and weight was observed all the way throughout the study, and to confirm the diabetic status, fasting blood glucose measurement was repeated on the day of euthanasia.

\section{After diabetes confirmed in animal}

Wounding: After diabetes was established in animals, with the help of punch biopsy machine (diameter of $6 \mathrm{~mm}$; Accu-punch) make a full thickness around wound at the upper back of each rat in every group. Wound were traced on $1 \mathrm{~mm}^{2}$ graph paper on the same day of wounding and consequently at a gap of 3 days up to $12^{\text {th }}$ day then on alternating days until healing was absolute. Changes in wound area were calculated on continuous mode and the speed of wound healing measured as given in the formula below. Implication in the healing of test groups is derived by comparing healed wound area on specific days with healed area of control group. ${ }^{2}$

Histopathology of wounds and measurements of percentage of wound healing by excision wound model was done in the following groups on $0,8^{\text {th }}$ and $12^{\text {th }}$ day:

Group 1: Control [vehicle].

Group 2: Positive control [standard povidone iodine]

Group 3: Treated with Carica Papaya.

Borders of the wounds were marked on a transparent paper by a fine tip permanent marker. The portion (in square millimetres) inside the borders of each tracing was determined plan metrically. The wound area of each animal was measured on 0 day, prearranged time period initially at $3 \mathrm{~h}$ post wounding and successive measurement of wound area from both the three groups was taken on days 4, 8, and 12 post wounding. The grades of wound measurements on different days were articulated as percentage wound contraction. The values were articulated as per cent values of the 0 day capacity and were intended by wilson's formula as follows:

$\%$ of Wound contraction $=\frac{(\text { day wound area }- \text { unhealed } \text { wound })}{(0 \text { day } \text { wound area })} \times 100$
Photographs of animals on $0,8^{\text {th }}$ and $12^{\text {th }}$ days post wounding of every group were taken.

\section{Results and discussion}

\section{Measurements of proportion of wound contraction on 0 day}

a. For Control Group 1, the \% of wound reduction was found to be $=2 \%$.

b. For Group 2, Positive control, the $\%$ of wound reduction was found to $b e=6 \%$.

c. For Group 3, Treated with Carica Papaya gel the \% of wound reduction was found to $\mathrm{be}=6 \%$.

\section{Measurements of percentage of wound contraction on $4^{\text {th }}$ day}

a. For Control Group 1, the \% of wound contraction was found to be $=6 \%$.

b. For Group 2, Positive control, the \% of wound contraction was found to $b e=23 \%$.

c. For Group 3,Treated with Carica Papaya gel the \% of wound contraction was found to be $=32 \%$.

\section{Measurements of percentage of wound contraction on $8^{\text {th }}$ day}

a. For Control Group 1, the \% of wound narrowing was found to be $=13 \%$.

b. For Group 2, Positive control, the \% of wound narrowing was found to $b e=42 \%$.

c. For Group 3, Treated with Carica Papaya gel the \% of wound narrowing was found to be $=57 \%$.

Measurements of percentage of wound contraction on $12^{\text {th }}$ day

a. For Control Group 1, the \% of wound reduction was found to be $=22 \%$.

b. For Group 2, Positive control, the \% of wound reduction was found to $b e=63 \%$.

c. For Group 3, Treated with Carica Papaya gel the \% of wound reduction was found to $\mathrm{be}=67 \%$.

On understanding the data obtained by the analysis of $\%$ of wound narrowing on these 4 constitutive days, it was observe that the wound healing property of povidone iodine and Carica Papaya gel were very close and Carica Papaya increase the wound healing improvement in diabetic rats (Figure 1).

\section{Wound healing photographs of wounds in rat on $8^{\text {th }}$ day}

Histological images of wound tissues (Histopathology) of group 1(control wounded non-treated), group 2 (positive control) and group 3 treated with Carica Papaya gel was done on $0,8^{\text {th }}$ and $12^{\text {th }}$ day (Figure 2). 


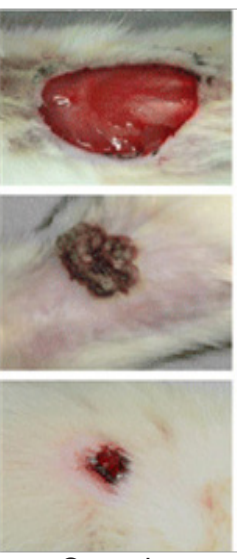

Group I

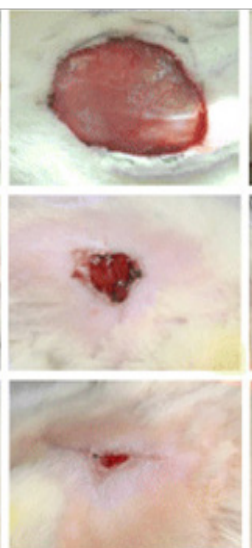

Group 2

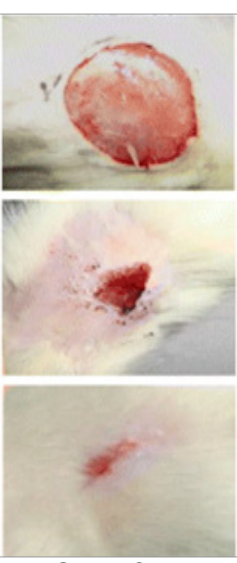

Group 3
Figure I Photographs of wounds recovery rate in rodents for the respective groups.

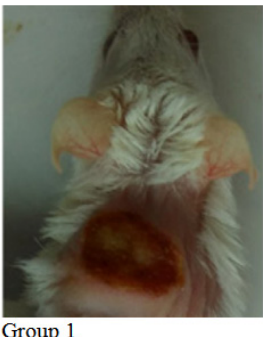

Group 1

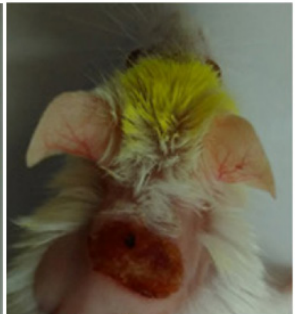

Group 2

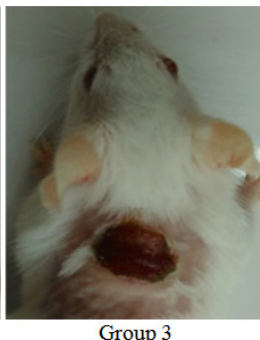

Group 3
Figure 2 Wound healing photographs of wounds in rat on $8^{\text {th }}$ day after wound formation in (Group I) Control wounded non-treated. (Group 2) Positive control. (Group 3) Treated with Carica Papaya.

\section{Histopathological images of groups on 0 day}

The histopathology of the wound curing slide represent that on day zero the scars and injury of tissue for all the three groups are approximately same (Figure 3).
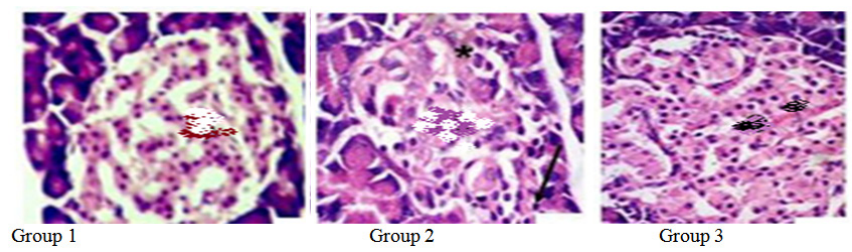

Figure 3 Histological changes during the wound-healing process on the 0 day. (Group I) Control wounded non-treated). (Group 2) Positive control. (Group 3) Treated with Carica Papaya.

\section{Histopathological images of groups on $8^{\text {th }}$ day}

The histopathology of the wound curing slide represent that on the eight day angiogenesis, collagen deposition, granulation, tissue formation, and wound narrowing take place more rapidly in group 2 and group three as compare to group 1. Even it was observed that collagen deposition and tissue development is greater in group 3 in the comparison of group 2 (Figure 4).

\section{Histopathological images of groups on $12^{\text {th }}$ day}

The histopathology of the wound curing slide represent that on day twelve the scars and injury of tissue for all the three groups are totally different. As group 2 and group 3, Carica Papaya debrided wounds

speedily, replacing sloughs with granulation tissue. It also enhanced quick epithelialisation, and inclusion of oedema from around the ulcer boundaries (Figure 5).
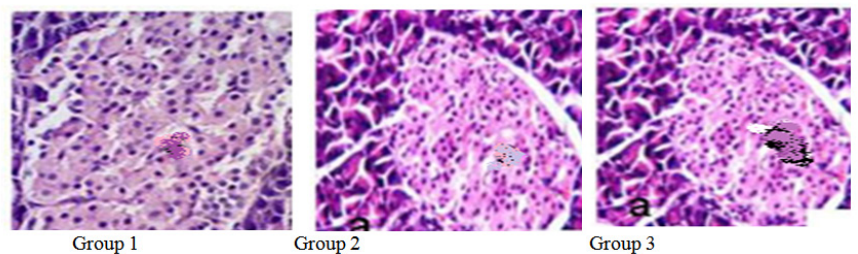

Figure 4 Histological changes during the wound-healing process on the $8^{\text {th }}$ day. (Group I) Control wounded non-treated. (Group 2) Positive control. (Group 3) Treated with Carica Papaya.
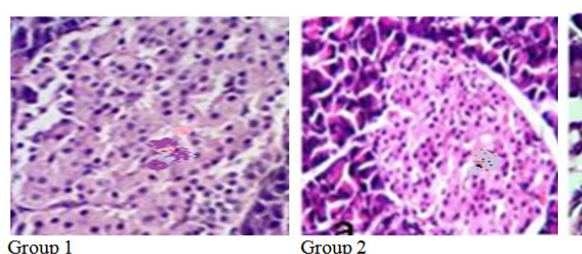
Group 2

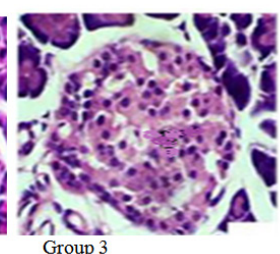

Figure 5 Histological changes during the wound-healing process on the $12^{\text {th }}$ day. (Group I) Control wounded non-treated. (Group 2) Positive control. (Group 3) Treated with Carica Papaya.

\section{Conclusion}

The following research was emphasized on the development of a newest topical therapeutic agent Carica Papaya; increase the wound curing process in diabetic rats. With this expectation we examine the healing proficiency of papaya latex formulated as 1.0 and $2.5 \%$ hydrogels. We created a full width around wound at the upper back of every rat in every group in wistar rats separated into three groups as following; Group-I (negative control) received no treatment. GroupII was treated with standard drug povidone iodine hydrogel (positive control). Group-III received the Carica Papaya hydrogel. The efficacy of treatment was estimated on the base of wound narrowing rate, wound healing photographs in rats and histopathological report of animals of group 1, group 2 and group 3. It was bring into being that Carica Papaya was a superb therapeutic agent, which used to improve the wound curing rate extensively in diabetic rodents.

\section{Acknowledgements}

The authors acknowledge Dr. Ashok Yadav Professor and staff of the Department of Pathology, Govt. Mahatma Gandhi Memorial Medical College and M.Y. Hospital Indore (Madhya Pradesh), India for providing histopathological facility and encouragement in carrying out the work.

\section{Conflict of interest}

The author declares no conflict of interest.

\section{References}

1. Wu KK, Huan Y. Streptozotocin-induced diabetic models in mice and rats. Curr Protoc Pharmacol. 2008;5:1-14.

2. Agarwal PK, Singh A, Gaurav K, et al. Evaluation of wound healing activity of extracts of plantain banana (Musa sapientum var. ) in rats. Ind J Exp Biol. 2009;47(1):32-40. 
3. Murthy S, Gautam MK, Goel S, et al. Evaluation of in vivo wound healing activity of Bacopa monniera on different wound model in rats. Biomed Res Int. 2013;972028.

4. Zhang X, Ookawa M, Tan Y, et al. Biochemical characterisation and assessment of fibril-forming ability of collagens extracted from Bester sturgeon Huso huso×Acipenser ruthenus. Food Chem. 2014;160:305312 .

5. Bowler PG. Wound pathophysiology, infection and therapeutic options. Ann Med. 2002;34(6):419-427.

6. Varoglu E, Seven B, Gumustekin K, et al. The effects of vitamin e and selenium on blood flow to experimental skin burns in rats using the ${ }^{133} \mathrm{Xe}$ clearance technique. Cen Eur Jour of Med. 2010;5(2):219-223.

7. Harding KG, Moore K, Phillips TJ. Wound chronicity and fibroblast senescence-implications for treatment. Int Wound J. 2005;2(4):364-368.

8. Mikhalchik EV, Anurov MV, Titkova SM, et al. Activity of antioxidant enzymes in the skin during surgical wounds. Bull Exp Biol Med. 2006;142(6):667-669.

9. Sairam K, Rao CV, Babu MD, et al. Prophylactic and curative effects of Bacopa monniera in gastric ulcer models. Phytomedicine 2001;8(6):423-430.

10. Singh HK, Rastogi RP, Srimal RC, et al. Effect of bacosides A and B on avoidance responses in rats. Phytotherapy Res. 1988;2(2):70-75.
11. Jyoti A, Sharma D. Neuroprotective role of Bacopa monniera extract against aluminium-induced oxidative stress in the hippocampus of rat brain. Neurotoxicology. 2006;27(4):451-457.

12. Holcomb LA, Dhanasekaran M, Hitt AR, et al. Bacopa monniera extract reduces amyloid levels in PSAPP mice. J Alzheimers Dis. 2006;9(3):243251 .

13. Rao CV, Sairam K, Goel RK. Experimental evaluation of Bacopa monniera on rat gastric ulceration and secretion. Indian J Physiol Pharmacol. 2000;44(4):435-441.

14. Sairam K, Dorababu M, Goel RK, et al. Antidepressant activity of standardized extract of Bacopa monniera in experimental models of depression in rats. Phytomedicine. 2002;9(3):207-211.

15. Goel RK, Sairam K, Babu MD, et al. In vitro evaluation of Bacopa monniera on anti-Helicobacter pylori activity and accumulation of prostaglandins. Phytomedicine. 2003;10(6-7):523-527.

16. Dorababu M, Prabha T, Priyambada S, et al. Effect of Bacopa monniera and Azadirachta indica on gastric ulceration and healing in experimental NIDDM rats. Indian J Exp Biol. 2004;42(4):389-397.

17. Gohil KJ, Patel JJ. A review on Bacopa monniera: current research and future prospects. International Jour of Green Pharm. 2010;4(1):1-9.

18. Sharath R, Harish BG, Krishna V, et al. Wound healing and protease inhibition activity of Bacoside-A, isolated from Bacopa monnieri Wettest. Phytother Res. 2010;24(8):1217-1222. 